Article

\title{
Contribution of Water Saving to a Stable Power Supply in Vietnam
}

\author{
Takayuki Otani ${ }^{1}$, Kanako Toyosada ${ }^{2}$ and Yasutoshi Shimizu ${ }^{3, *}$ \\ 1 ESG Promotion Department, TOTO Ltd., 2-1-1, Nakashima, Kokurakita-ku, \\ Kitakyushu City 802-8601, Japan; E-Mail: takayuki.otani@jp.toto.com \\ 2 Fukuoka Women's University, 1-1-1, Kasumigaoka, Higashi-ku, Fukuoka City 813-8529, Japan; \\ E-Mail: kanako.toyosada@fwu.ac.jp \\ 3 Water and Lifestyle Research Laboratory, 31-3, Munakata, Fukuoka 811-4141, Japan \\ * Author to whom correspondence should be addressed; E-Mail: yshimizu@wlrlab.com; \\ Tel./Fax: +81-940-32-7449.
}

Academic Editor: Miklas Scholz

Received: 15 May 2015 / Accepted: 5 June 2015 / Published: 15 June 2015

\begin{abstract}
In Vietnam, the rapid expansion of cities is exceeding the supply capacity for water and electricity, and restrictions on water supply and blackouts occur on a daily basis. In this study, the authors examined whether water-saving equipment could solve these problems. This paper focused on toilet bowls that consumed a large amount of water, and on showers for which heat consumption was high. In Vietnam, the main heat source for showers is the electric water heater, typically having a power consumption of 2500-4500 W. Although the current diffusion rate of such water heaters is just $13 \%$, their use will spread widely in the future. These heaters have already placed a peak load on electricity consumption in winter when a large amount of energy is consumed for heating water, and they will become a significant factor in blackout risks as their use becomes commonplace nationwide. It is clear that the introduction of water-saving showers will allow not only a more efficient use of water resources, but will also mitigate against the risk of blackouts.
\end{abstract}

Keywords: global warming; $\mathrm{CO}_{2}$ reduction; water; saving water; Vietnam 


\section{Introduction}

The United Nations' proposed "Millennium Sustainable Development Goals" will set the future direction for global sustainable development. The target year for the Millennium Development Goals, 2015 , is already here and discussions with respect to deciding upon the content of the next goals have started. Addressing water problems is considered to be one of the most important tasks to ensure sustainable development. Advanced nations have been carrying out research related to city water consumption and associated $\mathrm{CO}_{2}$ emissions [1-3].

The authors have also started discussing the nature of future goals by recognizing the role of water, based on its relation with energy [4]. The authors have shown that the creation of a water-saving society is one viable solution for sustainable development by using Japan and Vietnam as an example [5-7]. The results show that the spread of water-saving equipment could reduce $\mathrm{CO}_{2}$ emissions in Japan by $1 \%$ in 2020 (compared to $\mathrm{CO}_{2}$ emissions in 1990). For Vietnam, calculations show that total national emissions could be reduced by $8 \%$.

The authors also reported that the rapid expansion of cities has exceeded the supply capacity of water in Vietnam, and to prevent restrictions on water supplies, detached houses have elevated storage tanks installed [7]. The power consumption for storing water in elevated tanks accounts for 3\% of the total power consumption in Vietnamese houses. Our research showed that the main energy source for Vietnamese homes was electricity, and people used electricity to power shower water heaters.

However, as shown in Figure 1, the demand on the power supply exceeds supply capacity, and blackouts frequently occur. In addition, although it is said that the power supply will become stable in 2016 as a result of the development of new power sources, this estimate is based on the assumption that all power generation facilities operate stably, and the surplus ratio of power supply will be low [8]. Therefore, the authors have evaluated the contribution of water saving to a stable power supply. This study demonstrates the effects of water saving by examining the impact of city water consumption on the peak load of electricity.

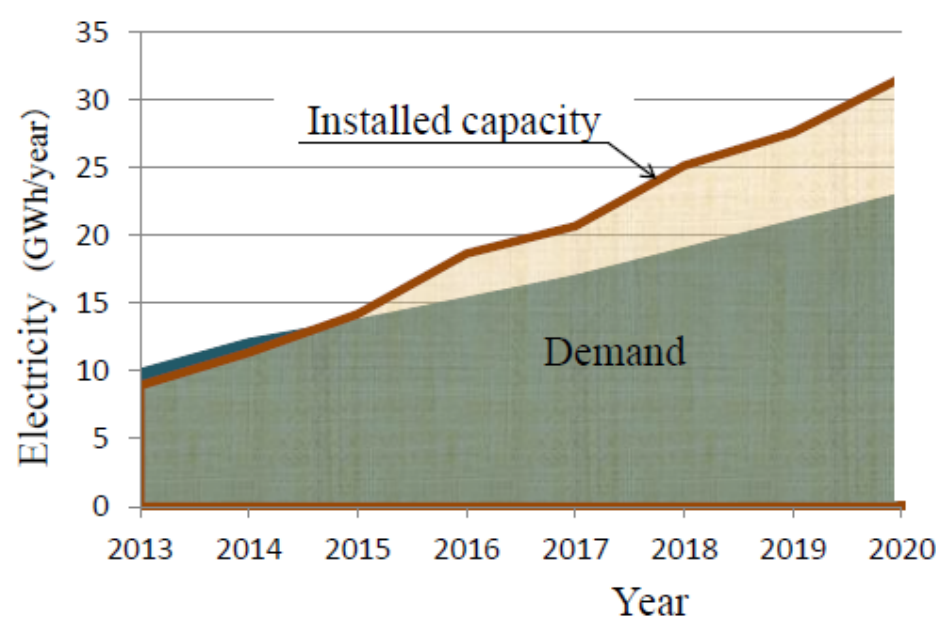

Figure 1. Power consumption forecast and power capacity in southern Vietnam (Vietnam Electricity Research 2012). 


\section{Analysis}

The authors evaluated water usage in houses in Vietnam on the basis of power consumption. The evaluation targets were toilets and showers. Water usage models and the evaluation coefficient were mentioned in a previous paper [7]. The toilet usage model used in the evaluation was 2.1 full flushes/person/day, and 4.8 half flushes/person/day. The shower usage model was 1.05 showers/person/day, $8.9 \mathrm{~min} /$ per shower, and the shower water temperature was $36.3{ }^{\circ} \mathrm{C}$. The number of times a toilet was used, the number of times a shower was used, and the time for that purpose were not different from the research results for Japan [9-11]. The performance of current toilet bowls was $6.0 \mathrm{~L} /$ full flush and 5.0 L/half flush, and that of water-saving toilet bowls was $4.8 \mathrm{~L} /$ full flush and $3.0 \mathrm{~L} /$ half flush. The flow rate of current showerheads was $10 \mathrm{~L} / \mathrm{min}$, and that of water-saving showerheads was $6.5 \mathrm{~L} / \mathrm{min}$. For the energy consumption rate of water, the values in Table 1 were used [7].

Table 1. Energy consumption rate of water in Vietnam.

\begin{tabular}{cc}
\hline Process & Energy Consumption Rate of Water $\left.\mathbf{( M J} / \mathbf{m}^{\mathbf{3}}\right)$ \\
\hline Waterworks system & 1.44 \\
Sewer system & 1.05 \\
Water supply system in a house & 1.99 \\
\hline
\end{tabular}

\section{Results and Discussion}

The coverage of the waterworks system in Vietnam is $22 \%$ and that of the sewerage system is $18 \%$. Most urban areas, such as Hanoi and Ho Chi Minh City, are served by waterworks and sewerage systems, and houses in the area are equipped with flush toilets and showers [7]. According to the water infrastructure plan of the Vietnamese government, the country aims to provide $90 \%$ of urban areas with waterworks system access, and $50 \%$ to $70 \%$ of rural areas in 2015 , and by 2025 provide a $24-\mathrm{h}$ water supply service for $100 \%$ of the country. Under the plan, rapid development is expected [12].

In this study, we evaluate the environmental contribution potential by calculating the carbon crediting scheme [7]. In the crediting scheme, the credit amount is evaluated as the difference between emissions following implementation of a low-carbon project and a near-future baseline. A conceptual diagram is shown in Figure 2. The near-future baseline (the Business as Usual, or BaU line) is a forecast that assumes that the water infrastructure will spread throughout the whole country.

The evaluation scope was set as the same as the previous studies, covering overall water infrastructure from waterworks systems, plumbing systems, and sewer systems [5-7].

\subsection{Effect of Water Saving on Power Supply}

Based on the development of water infrastructure, assuming a society in which the current most common flush toilet bowls and showers in Vietnam are used in all houses as a baseline (the Business as Usual, or BaU line), the authors evaluated the reduction potential at the time when a water-saving project is implemented. With respect to showers, the authors assumed that the electric water heaters currently used would be adopted widely. Table 2 shows the performance of these electric water heaters. 


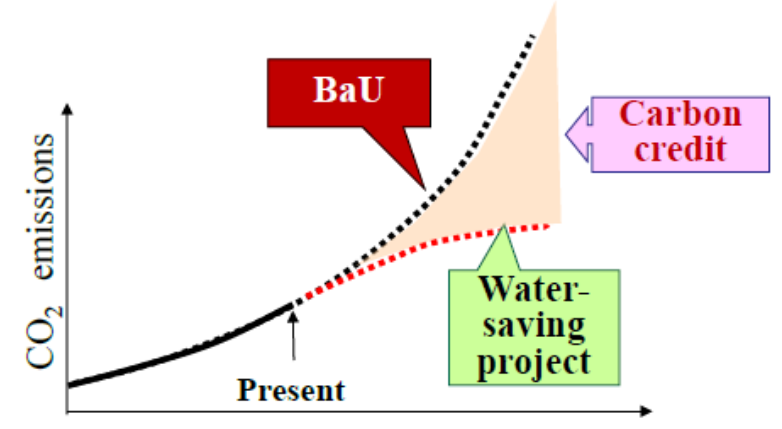

Figure 2. Conceptual diagram of water-saving project evaluation in developing countries.

Table 2. Water heater performance used in Vietnam.

\begin{tabular}{ccc}
\hline Item & Instantaneous Electric Water Heater & Storage Electric Water Heater \\
\hline Appearance & 40 & 2500 \\
Power consumption $(\mathrm{W})$ & 0 & 60 \\
Max. supply temperature $\left({ }^{\circ} \mathrm{C}\right)$ & 4500 & $10-30$ \\
Storage capacity $(\mathrm{L})$ &
\end{tabular}

According to research in Hanoi and Ho Chi Minh City, the average preferred shower temperature is $36{ }^{\circ} \mathrm{C}$ in both cities [7]. The authors calculated the electric power load generated when showers were taken, according to the energy required to heat the water in both cities to the desired shower water temperature, as shown in Figure 3. It was assumed that the energy efficiency of the water heaters was $80 \%$, the same as that of the gas water heaters usually used in Japan [13], and we calculated the water preservation and electricity consumption reduction potential that would be achieved by the spread of water-saving equipment (Figure 4). For the current water heater diffusion rate, the authors used 13\%, found by weighted average with the population in urban areas and the population in rural areas, based on Table $3[8]$.

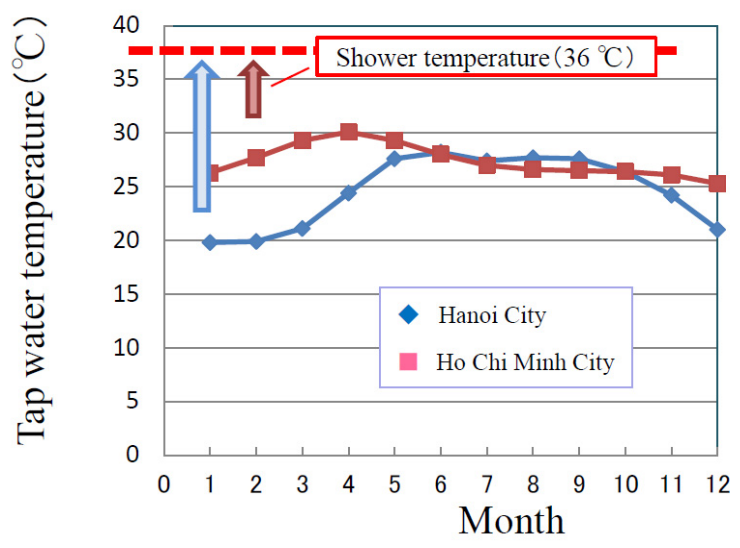

Figure 3. Water and shower temperature in Hanoi and Ho Chi Minh City. 


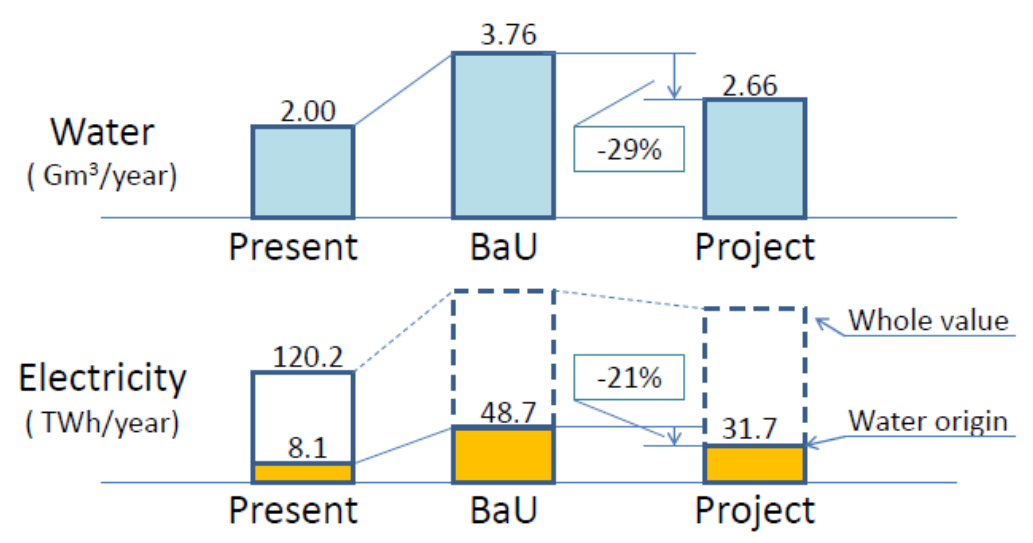

Figure 4. Effect of water saving on water and electric power supply in Vietnam. BaU: Completion of water infrastructure building; Project: Implementation of water-saving project.

Table 3. Domestic electrical appliance diffusion rate in Vietnamese urban areas (\%).

\begin{tabular}{|c|c|c|c|c|c|c|c|c|}
\hline \multirow{2}{*}{ Item } & \multicolumn{2}{|c|}{2004} & \multicolumn{2}{|c|}{2006} & \multicolumn{2}{|c|}{2008} & \multicolumn{2}{|c|}{2010} \\
\hline & Urban & Rural & Urban & Rural & Urban & Rural & Urban & Rural \\
\hline Refrigerator & 45.8 & 6.8 & 53.9 & 11.2 & 64.1 & 19.6 & 63.8 & 29.2 \\
\hline PC & 16.3 & 1.3 & 21.3 & 2.6 & 28.9 & 4.8 & 38.2 & 7.6 \\
\hline Television & 94.9 & 61.4 & 102.1 & 74.3 & 108.6 & 85.7 & 97.6 & 80.7 \\
\hline Air-conditioner & 8.0 & 0.3 & 12.0 & 0.5 & 17.3 & 1.0 & 26.2 & 2.1 \\
\hline Water heater & 18.0 & 1.1 & 22.5 & 2.0 & 26.6 & 3.8 & 28.9 & 6.3 \\
\hline
\end{tabular}

According to the authors' research, not only Vietnam, but also China, Indonesia, Malaysia, and other countries using $200 \mathrm{~V}$ or higher electric power, commonly use electric water heaters for hot water supply. As electric heaters become more popular, electricity consumption deriving from water usage will increase five-fold compared to the current consumption in Vietnam. If the use of water-saving showers can be made more widespread, the increase in electricity consumption can be reduced by $21 \%$, as shown in Figure 4. In this figure, the water-preservation potential of the water-saving project is also shown.

When implementing a water-saving project, the system through which high performance equipment spreads is important. For a shower, it is important to attain both basic quality, including safety and comfort, as well as water-saving performance. The creation of a water-saving equipment certification system is progressing under a water-saving Joint Crediting Mechanism (JCM) project.

\subsection{Effect of Water Saving on Peak Load of Electricity Consumption}

In Vietnam, the rapid development of cities has caused frequent blackouts. In the summertime of 2010, in big cities such as Hanoi and Ho Chi Minh City, blackouts occurred for $48 \mathrm{~h}$ per week [12]. A blackout occurs when the peak of electricity consumption exceeds the supply capacity. Based on this, the authors extracted the electricity consumption conditions in Vietnam by season, as shown in Figure 5. Additionally, Table 4 shows the electricity consumption of domestic electrical appliances that are widely used in Vietnam. 


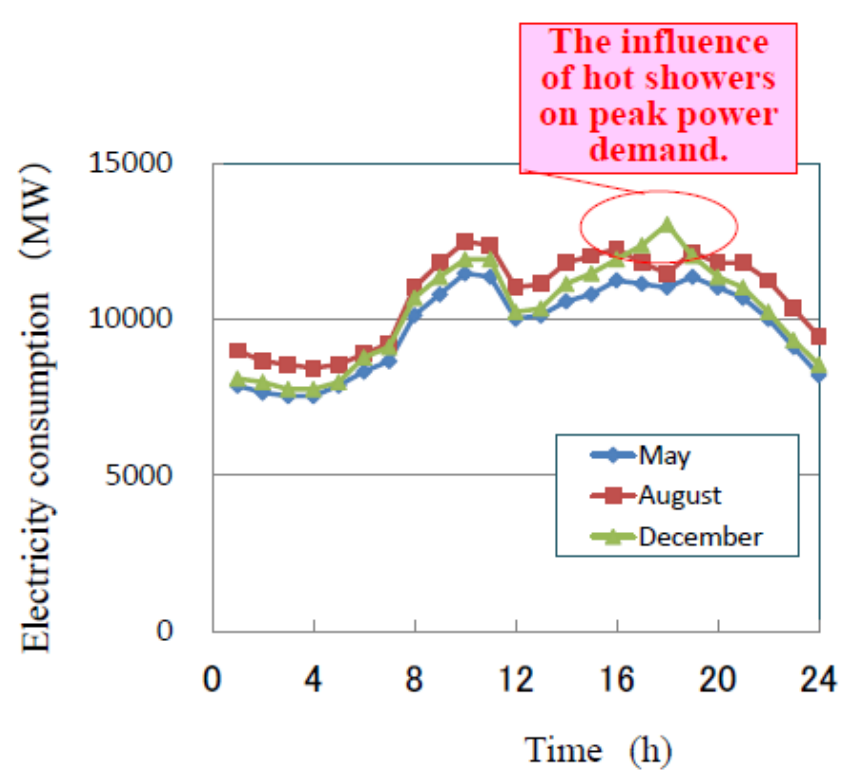

Figure 5. Electricity consumption in Vietnam.

Table 4. Electricity consumption of electrical appliances in Vietnam.

\begin{tabular}{cccccc}
\hline Item & Refrigerator & PC & Television & Air-Conditioner & Water Heater \\
\hline Electricity consumption (W) & $150-600$ & $50-150$ & $150-200$ & $100-1000$ & $2500-4500$ \\
\hline
\end{tabular}

As can be seen from Table 4, the electricity consumption of electric water heaters is extremely high compared to other electrical appliances. Additionally, research into water usage in Vietnam, for which an outline has already been reported [6], showed that people in Vietnam took a shower once a day after getting home at around 6:00 P.M. Although the diffusion rate of electric water heaters for showers is $13 \%$, the authors can see how electric water heaters affect electricity consumption as the electricity consumption peak appears around 6:00 P.M. in winter.

The effect of electrical appliances on blackouts usually comes to the fore in summer when the load of air-conditioners in the daytime. However, the electricity consumption peak in the daytime in summer supposedly arising from air-conditioners is almost the same as that in the evening in winter arising from electric water heaters. Therefore, we have to pay attention to the effect of electric water heaters, which, hitherto, had not been considered much as a cause of blackouts.

Concerning the reduction in the load of air-conditioners, a project that promotes the diffusion of highly effective inverter air-conditioners using the Japanese Joint Crediting Mechanism scheme has started. To reduce the power load of electric water heaters, a change of heat sources, such as a utilization of solar heaters, and a reduction of heat consumption by water saving can be considered as viable measures.

To promote the use of solar heaters, a trial project has started in Vietnam. However, a solar heater requires the installation of a large water tank on the roof of a house, and the installation of such a facility requires reinforcement of the roof. Therefore, in practice, a tank can be installed on only a newly built residential building. In addition, as the unit cost of a solar heater is high, the availability of solar heaters has not been promoted. Additionally, as the unit cost of a propane gas tank is high, gas water heaters have not become popular. 
Therefore, the authors consider that electricity will remain the main source of power for water heaters, and to reduce the peak electricity consumption load arising from showers, the introduction of water-saving showers would have an immediate effect.

\section{Conclusions}

The Japanese government uses environmental technology and products and actively promotes Green Growth in order to lead developing countries towards becoming low-carbon societies faster. The Joint Crediting Mechanism scheme, under which $\mathrm{CO}_{2}$ reductions in developing countries are converted into a monetary value, which the Japanese government purchases to offset the $\mathrm{CO}_{2}$ emissions of Japan by the application of Japanese technology and products, is a support project for developing nations. The authors have evaluated the potential reduction in $\mathrm{CO}_{2}$ emissions by water-saving equipment in Japan, China, and Vietnam, and concluded that they will prove effective in the prevention of global warming. As a result, in Vietnam, a $\mathrm{CO}_{2}$ reduction project is appearing in concrete form.

In this research, the authors evaluated the effect of water saving on offsetting the shortage in electricity supply, which is a serious problem in Vietnam and other developing countries. The authors found that in the ASEAN area, in countries, such as Vietnam, many people used electricity for heating shower water, and that this constituted an electricity consumption peak load. Also the authors clarified that the future diffusion of electric water heaters will increase the risk of blackouts.

Now, plans are underway for a large-scale water-saving JCM project in Vietnam. The electricity peak-load mitigation effect by water-saving shower diffusion will be demonstrated through this project.

\section{Acknowledgments}

This survey was conducted in Vietnam as a part of the "Global Warming Mitigation Technology Promotion Project (FY2012)" of the Ministry of Economy, Trade and Industry of Japan, and as a part of the "Project to Support the Large-Scale Formation of Joint Crediting Mechanism Programs to Realize Low Carbon Societies in Asia (FY2013)" of the Ministry of the Environment of Japan.

\section{Author Contributions}

The survey and analysis in this study were carried out by Takayuki Otani and Kanako Toyosada under the direction and supervision of Yasutoshi Shimizu. The first draft of the manuscript was prepared by Takayuki Otani, and later versions were revised and edited extensively by Yasutoshi Shimizu before publication. All authors discussed the results and commented on the manuscript at all stages.

\section{Conflicts of Interest}

The authors declare no conflict of interest.

\section{References}

1. Environment Agency. Greenhouse Gas Emissions of Water Supply and Demand Management Options; Science Report-SC070010; Environment Agency: Bristol, UK, 2008. 
2. Quantifying the Energy and Carbon Effects of Water Saving 2009. Available online: http://www.eauc.org.uk/quantifying_the_energy_and_carbon_effects_of_wa (accessed on 1 June 2015).

3. Energy Use in the Provision and Consumption of Urban Water in Australia and New Zealand 2008. Available online: http://www.clw.csiro.au/publications/waterforahealthycountry/2008/wfhc-urbanwater-energy.pdf (accessed on 1 June 2015).

4. U.N.-Water Annual Zaragoza Conferences. Available online: http://www.un.org/waterforlifedecade/ water_and_energy_2014/index.shtml (accessed on 1 May 2015).

5. Shimizu, Y.; Toyosada, K.; Nakashima, K. Prediction of $\mathrm{CO}_{2}$ emissions associated with residential plumbing equipment. J. Soc. Heat. Air-Cond. Sanit. Eng. Jpn. 2010, 163, 11-18.

6. Shimizu, Y.; Toyosada, K.; Yoshitaka, M.; Sakaue, K. Creation of carbon credits by water saving. Water 2012, 4, 533-544.

7. Otani, T.; Toyosada, K.; Shimizu, Y. $\mathrm{CO}_{2}$ reduction potential of water saving in Vietnam. Water 2015, 7, 2516-2526.

8. JETRO Hanoi, Vietnam Electricity Survey 2013. (In Japanese). Available online: http://www. jetro.go.jp/jfile/report/07001271/vietnamelectricity2013-2.pdf (accessed on 1 May 2015).

9. Toyosada, K.; Shimizu, Y.; Iio, A.; Sakaue, K. Quantification of environmental impact reduction effect resulting from use of water-saving toilet bowls. J. Soc. Heat. Air-Cond. Sanit. Eng. Jpn. 2013, 193, 1-8.

10. Toyosada, K.; Shimizu, Y.; Dejima, S.; Yoshitaka, M.; Sakaue, K. Evaluation of the potential of $\mathrm{CO}_{2}$ emission reduction achieved by using water-efficient housing equipment in Dalian, China. In Proceedings of the 38th International Symposium of CIB W062 on Water Supply and Drainage for Buildings, Edinburgh, UK, 28 August 2012; pp. 27-30.

11. Kimura, H.; Hirose, A.; Toyosada, K.; Shimizu, Y.; Iio, A.; Sakaue, K. Study on the Modeling of the Bathing Behavior in Japan. In Proceeding of the Society of Heating, Air-conditioning and Sanitary Engineers of Japan, Sapporo, Japan, 5 September 2012; pp. 25-28.

12. Vietnam Water and Sanitation Sector Assessment Report 2011. Available online: http://www.wpro. who.int/vietnam/topics/water_sanitation/watsan_sector_report_vietnam_2011.pdf (accessed on 1 May 2015).

13. A committee to promote household energy efficiency and home security, Approach Book to promote household energy efficiency and home security 2006. (In Japanese)

(C) 2015 by the authors; licensee MDPI, Basel, Switzerland. This article is an open access article distributed under the terms and conditions of the Creative Commons Attribution license (http://creativecommons.org/licenses/by/4.0/). 